\title{
GRACIA Y GOBIERNO EN LA ADMINISTRACIÓN VALENCIANA DEL SEISCIENTOS. HACIA NUEVOS CONSENSOS*
}

\author{
Teresa CANet Aparisi \\ Universidad de Valencia
}

Fecha de recepción: octubre 2014

Fecha de aceptación: marzo 2015

Cuando tras una serie de intentos fallidos se reunieron por fin las Cortes valencianas en $1645^{1}$, la Monarquía de Felipe IV atravesaba uno de sus momentos más difíciles. Los frentes internos provocados por la secesión de Cataluña y Portugal se sumaban al exterior, preexistente y agravado desde 1635 por la declaración de guerra de Francia. En Valencia el período que siguió a la reunión parlamentaria de 1626 (especialmente la década de los años treinta) había estado marcado por fuertes tensiones entre el rey y el reino; venían provocadas tanto por la resistencia estamental a las exigencias militares de la corona - planteadas en forma de levas y servicios- como por las luchas internas de la nobleza local, traducidas en continuos enfrentamientos que avivaban los vuelos de un bandolerismo endémico. Ese clima -especialmente en materia de cooperación militar- empezó a cambiar a comienzos de los años cuarenta, momento calificado por L. Guía como «fase crucial del buen entendimiento entre la monarquía y los estamentos valencianos $»^{2}$. La proximidad del frente catalán y la presencia de tropas francesas en la misma frontera del reino habrían sido determinantes en el establecimiento de un

\footnotetext{
* Este trabajo se ha realizado en el marco del proyecto HAR2014-53298-C2-1 («Nuevas perspectivas de Historia Social en los territorios hispánicos del Mediterráneo Occidental en la Edad Moderna»), financiado por el Ministerio de Economía y Competitividad.

1. Estudiadas por Guia Marin, Ll.: Cortes del reinado de Felipe IV. II. Cortes valencianas de 1645, Valencia, Publicaciones del Departamento de Historia Moderna, Monografías y Fuentes, 10, 1984. Tanto el contexto que rodeó la convocatoria y celebración como su contenido legislativo son exhaustivamente diseccionados por el autor en el amplísimo «Estudio Preliminar» de casi 200 páginas que acompaña la edición del corpus legislativo de 1645 .
}

2. Las coordenadas del mismo son explicadas por el autor en: «Estudio Preliminar», op. cit., pp. 28-37. 
ambiente más propicio a la colaboración. La habilidad del entonces virrey de Valencia, duque de Arcos, fue otro elemento de peso para facilitar el entendimiento entre la corte y el territorio. Levas, alojamientos de tropas reales y socorros continuados a las plazas de Tarragona, Tortosa y Rosas tradujeron los efectos de la nueva actitud.

En ese contexto, forzado por la emergencia militar pero también por los problemas de orden público que los enfrentamientos intra-nobiliarios suscitaban y por los procedimientos expeditivos que los representantes reales usaban para controlarlos, surgieron las demandas de celebración de Cortes. Convocadas en el verano de 1645, se inaugurarían finalmente en octubre de aquel año. De su contenido legislativo se han destacado dos cuestiones por el número de disposiciones a que dieron lugar. Se trata de, por un lado, la reglamentación de las embajadas de contrafuero y, por otro, de los conflictos de competencias de jurisdicción que enfrentaban a la Audiencia con el resto de esferas y órganos de administración y gobierno del territorio. ${ }^{3}$ Dos materias muy elocuentes de cara a explicar la creación, entonces aprobada, de las plazas de capa y espada en el Consejo de Aragón y en la sala criminal de la real Audiencia. Desde fechas tempranas los estamentos habían manifestado en las diferentes reuniones de las Cortes valencianas su malestar hacia las actuaciones del tribunal. En ese marco, nobleza y clero reclamaron el derecho a tener una representación, como tales, dentro de la Audiencia. En definitiva, la oposición regnícola a la proyección jurisdiccional y política del alto tribunal fue constante a lo largo de casi toda la vida del organismo ${ }^{4}$. Las denuncias y peticiones formuladas por el reino en 1645 contra el órgano no constituían, por tanto, ninguna novedad salvo por el hecho de que a esta altura del siglo XVII la implicación de miembros de la magistratura en la guerras nobiliarias había experimentado un significativo incremento, al mismo tiempo que la represión de tales comportamientos desde las instancias virreinal y de corte se había también endurecido. ${ }^{5}$ Todas esas circunstancias obligan a valorar la instauración de las plazas de capa y espada desde la doble perspectiva de la oportunidad y de la función.

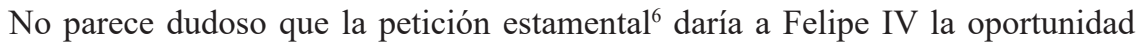
de recompensar al reino por la colaboración prestada en la guerra de Cataluña y la manifiesta fidelidad en la etapa de crisis. La medida tenía, en tal sentido, un marcado carácter político. Además el orden más beneficiado por esta gracia real era la nobleza pues de sentar a tres de sus miembros (subjectes de capa y espasa, según se recogía en la petición de 1645) en el Consejo de Aragón (1) y en la Audiencia (2) como consejeros en materias de gracia y gobierno se trataba. Tanto la demanda de los brazos como

3. Para una detallada visión de las materias jurídico institucionales contempladas en estas Cortes hay que acudir al análisis de GuIA, L1.: «Estudio Preliminar», op. cit., pp. 105-110.

4. No me extenderé sobre una cuestión ampliamente analizada en CANET APARISI, T.: La Audiencia valenciana en la época foral moderna, Valencia, Edicions Alfons el Magnánim, 1986, especialmente pp. 75-90.

5. Ambas circunstancias son también recogidas por GuiA, Ll.: «Estudio Preliminar», op. cit., pp. 37-45. Por su parte, CASEY, J.: El Reino de Valencia en el siglo XVII, Madrid, Edit. Siglo XXI, 1983, pp. 220-221 ya señaló las implicaciones de determinados jueces de la Audiencia con el bandolerismo nobiliario.

6. Materializada en el fuero 9 recogido en GuIA, L.: Cortes del reinado de Felipe IV. II, pp. 211. 
aceptación de la misma por el rey dejaban muy claro que los nuevos ministros no tendrían competencias en materias contenciosas, dado que carecían de formación letrada. Entraban a formar parte de la sala criminal de la Audiencia -ámbito que les acogería en adelante- como consejeros y, en consecuencia, como asesores del lugarteniente real. La financiación de las nuevas plazas provocó cierto debate entre el Consejo de Aragón y la Junta de materias, que se arrastraría hasta la publicación de las decretatas. Una puntualización deslizada por el soberano en torno a esa cuestión sirvió para señalar que en Valencia principiaba la práctica de una gracia extensible, si se ofrecía el caso, a los otros territorios de la Corona de Aragón. Para enfatizar el hecho señalaba: Plau a sa magestad..., reservant-se facultat en la plaça del Consell Supremo, que ha de pagar sa magestat, de concedir aquesta alternativa a los demés regnes d'esta Corona, començant esta vegada per València. ${ }^{7}$ Establecer la funcionalidad real de estos ministros-consejeros dentro del órgano que colaboraba con el virrey en el gobierno del reino es el propósito del presente análisis.

\section{POTESTADES VIRREINALES: ENTRE LA LIMITACIÓN Y EL EJERCICIO ASESORADO}

Las funciones asignadas a los ministros de capa y espada nos obligan a detenernos en quién y cómo se desarrollaban dichas actuaciones en el marco de la administración valenciana. La respuesta conduce necesariamente a la figura de los representantes personales del monarca en el reino, los virreyes, y remite a la evolución experimentada por la institución en el período moderno y, más concretamente, a lo largo del XVII.

Desde el trabajo pionero de J. Lalinde ${ }^{8}$ sobre la institución hasta las más recientes investigaciones sobre ejercicios concretos en los diversos territorios de la Corona de Aragón, hemos podido constatar la distorsión manifiesta entre las amplísimas competencias atribuidas a los representantes personales del soberano en los territorios desde el plano teórico y las restricciones impuestas en el ejercicio práctico de las mismas. La sutil combinación de elementos concurrentes en el juego de equilibrios que exigía el gobierno por delegación, la necesaria adaptación a circunstancias de estructura o coyuntura y un pragmatismo político siempre presente convirtieron esta institución, universal para el conjunto de territorios de la Corona de Aragón, en una instancia singular en cada contexto por adaptación al mismo. En otros lugares he insistido en el «vaciado» de ejercicio efectivo de la función judicial del virreinato valenciano desde la creación de la real Audiencia; una tendencia progresivamente incrementada desde mediados del XVI hasta los años 70 de dicha centuria y en la que no es necesario insistir por conocida. Las funciones de gobierno y gracia atribuidas al virrey van a ser ahora objeto de nuestra atención.

Deberemos realizar una sistematización, necesariamente apresurada, de las potestades gubernativa y graciosa atribuidas a los lugartenientes reales para mejor com-

7. Ibidem, pp. 211.

8. Lalinde Ababía, J.: La institución virreinal en Cataluña (1471-1716), Barcelona, 1964. 
prender el sentido de las plazas de capa y espada en la sala criminal de la Audiencia valenciana. Dentro de la institución, en tanto que tribunal de justicia, la esfera criminal por su relación con el orden público era la que ofertaba al virrey una mayor posibilidad de presencia y actuación, a diferencia de las materias civiles mucho más técnicas. Pero, en cualquier caso, la intervención -ocasional- del virrey en el proceso penal quedaba siempre sometida al voto mayoritario de los jueces y en las cuestiones de tal naturaleza no podrían intervenir tampoco los ministros de capa y espada por su condición de meros consejeros, o dicho en negativo: porque no eran jueces.

En la esfera política, o gubernativa, era la plantilla completa de la Audiencia (una sala criminal y dos salas civiles, cuando se crearon las plazas de capa y espada) la que como cuerpo y colegio asistía al virrey, siempre atendiendo a su convocatoria, para tomar decisiones en torno a materias no contenciosas. En determinadas circunstancias el lugarteniente real recurría a la convocatoria del Consejo Real -en sentido ampliodel que formaban parte los ministros reales que encabezaban las instituciones y donde los oficiales de capa y espada (portantveus de general gobernador, baile general, maestre racional y lugarteniente de tesorero general) tenían un significativo peso. Si antes de 1645 la participación de la nobleza en el gobierno del reino se había inscrito en esos parámetros de ejercicio, cabe preguntarse qué finalidad perseguía el hecho de llevar más miembros de dicho estamento al entorno curial del virreinato; por qué se integraba a la clase militar, como tal, en aquella sala de la Audiencia, la criminal, que de manera más cotidiana y directa intervenía en la determinación de las cuestiones de gobierno del reino y, teóricamente, también en la administración de la gracia real.

Es bien conocida la dificultad que entraña rastrear las actuaciones de gracia y gobierno a nivel regnícola, debido tanto a la naturaleza de aquellas como al carácter de las fuentes documentales. A diferencia de otras instituciones representativas (municipio, juntas estamentales...) las de la realeza no se mostraron especialmente cuidosas a la hora de recoger las actuaciones conducentes a la toma de decisiones en este orden. Quizás porque el registro de las disposiciones emanadas y las órdenes de ejecución de las decisiones ocupaban su mayor dedicación y absorbían los recursos disponibles. Quizás porque los lugartenientes reales actuaban de manera expeditiva, sin necesidad de articular las amplias consultas elevadas por el Consejo Supremo a los monarcas a la hora de formar criterio en la resolución de las cuestiones planteadas. Sea cual fuere el motivo, la realidad que el investigador constata es la ausencia de actas que recojan el desarrollo de tales procedimientos, salvo que estos sean referenciados de manera esporádica en algún tipo de correspondencia o consulta.

Sin embargo esa situación experimentó un cambio cualitativo desde mediados del siglo XVII, coincidiendo tanto con la llegada del duque de Montalto al gobierno del reino, como, un poco antes, con la creación de las plazas de capa y espada dentro de la Audiencia. La decisión del aristócrata italiano en 1652, poniendo en ejecución la real orden dirigida por Felipe IV al virrey marqués de Povar en 1624, nos permite hoy disponer de una amplísima colección de disposiciones reales sobre diferentes aspectos y materias relativas al gobierno del reino que se extiende hasta el final del régimen foral en 1707. Además, la especial riqueza de contenido de los informes enviados a la corte 
por el virrey Montalto resulta esencial para esclarecer el tema que nos proponemos ${ }^{9}$. Con acertado criterio, don Luis de Moncada remitía a la corte una misiva en la que la real orden, hasta entonces incumplida, y su decisión de ejecutarla se calificaban como «más necessaria...precaución que en otro cualquier reino, quanto más de ordinario se ofrecen materias de embarazo ya con los fueros, ya con las pretensiones de la ciudad, en que deveremos guiarnos por lo que estuviere resuelto por V(uestra) M(agestad) en paridad de casos ${ }^{10}{ }^{10}$. La capacidad de gestión de este noble italiano, antes virrey de Sicilia (1635-1639) y de Cerdeña (1645-1648) $)^{11}$, encontraba en esta vía una nueva forma de expresarse. Pero convendrá centrarnos en las potestades virreinales en las que, aparentemente, debían empezar a colaborar los ministros de capa y espada nombrados para la sala criminal de la Audiencia.

9. Archivo del Reino de Valencia (en adelante ARV), Real Cancilleria (en adelante RC), Epistolarum,. Los seis registros que componen la serie comprenden el período 1652-1707. En este trabajo no se utilizan en su totalidad. Don Luis de Moncada, duque de Montalto quiso dar cumplimiento al capítulo 58 de las extensas «Instrucciones» que se le habían entregado para el gobierno de Valencia. Se le indicaba allí que sus predecesores no habían cumplido la real orden de 1624, dirigida al marqués de Povar y en la que se ordenaba recopilar en registro único de Cancillería todas las disposiciones reales relativas al gobierno del reino en cualquiera de sus aspectos. Montalto, consciente de la dificultad de administrar sin el seguro respaldo de las decisiones regias, en una etapa tensa y problemática como la que afrontaba, puso en ejecución la real orden de 1624, recuperando para sí un sistema del que ya había hecho uso en Sicilia donde, según su propio testimonio, «habia experimentado igual desorden». Asesorado por los «ministros desta Audiencia», Montalto propuso como encargado del registro al escribano Vicente Ferrera, por entonces lugarteniente de protonotario en el reino. Sería desde entonces el responsable de «cobrar todos los despachos de Vuestra Magestad y registrarlos por el mismo original o por copia que se le dará de la secretaría quando al virrey le importe conservar los originales en su poder». La propuesta del virrey fue aceptada y el nombramiento se expedía en diciembre de 1652, siendo el vicecanciller Cristóbal Crespí de Valldaura el encargado de comunicar el hecho a Montalto. En adelante este cometido debía recaer siempre en un escribano de mandamiento, nombrado por el rey a propuesta del virrey; tendría carácter perpetuo, «sin mudarse con los virreyes», para facilitar la continuidad de la labor. En Ibidem, Registro 590, fols. $2 \mathrm{v}^{{ }^{\mathbf{o}}}$ y $3 \mathrm{r}^{\mathrm{o}}{ }^{\mathrm{o}} \mathrm{v}^{\mathrm{o}}$

10. ARV, RC, Epistolarum, Reg. 590, fol. 3r. ${ }^{\circ}$ Real de Valencia, 13-X-1652. Sobre la figura y carrera política de Luis Guillermo de Moncada-Aragón y La Cerda, VII duque de Montalto, resultan imprescindibles los trabajos de PILO, R., «Juegos de Cortes en la época barroca: Éxitos y derrotas de los duques de Montalto», en Martinez Millán, J. y Marzal Lourenço, M. a P. (Coords.): Las relaciones discretas entre las Monarquías Hispana y Portuguesa: Las casas de las Reinas (siglos XV-XIX), Vol. II, Madrid, 2008, pp. 1429-1442; «Casi todos los hombres del Cardenal Moncada. La conjura de otoño (octubre de 1668-marzo de 1669), en De Bernardo Ares, J. M. (Coord.): La sucesión de la Monarquía Hispánica, 1665-1725. I. Lucha política en las Cortes y fragilidad económica-fiscal en los Reinos, Córdoba, 2005, pp. 257-275; «In Spagna: Il ritorno dei Moncada», en ScAlisi, L. (a cura di): La Sicilia dei Moncada, Catania, 2006. El mejor conocedor de la gestión de Montalto en Valencia sigue siendo GuIA, L1., como acreditan, entre otros, los siguientes trabajos: «Los estamentos valencianos y el duque de Montalto. Los inicios de la reacción foral», en Estudis. Revista de Historia Moderna, 4 (1975), pp. 129-145 y «Els virreys i la práctica del govern. Serveis a la monarquía i orde public a València i Sardenya a mitjan segle XVII» en Sardenya, una historia próxima. El regne sard a l'época moderna, Catarroja-Barcelona, 2012, pp. 43-61.

11. GuIA, L1.: Sardenya, una historia próxima, pp. 49-54 ha señalado este rasgo sobresaliente en la personalidad de Montalto y su constatación documental. 


\section{LA ADMINISTRACIÓN DE LA GRACIA: UN EJERCICIO VIGILADO}

La potestad graciosa atribuida a los virreyes permitía a éstos remitir penas, componer delitos y, en determinadas circunstancias, extender guiatges y salvoconductos; también conceder títulos nobiliarios y privilegios militares, licencias de suplementos de edad, exenciones de derechos e impuestos, licencias para tener boticas o imponer sisas y títulos para ejercer la cirugía, la medicina y el notariado. Cuando el virrey ejercía esta potestad lo hacía, en algunos casos, sin someterse a ningún otro organismo, como era el caso de la actividad judicial. Siendo la dispensación de gracia el ámbito de competencias cuyo ejercicio efectivo más esperaban los súbditos, resultó ser el que más restricciones recibió de parte de los monarcas como en su momento señalara J. Lalinde ${ }^{12}$. La limitación de la potestad graciosa de los virreyes afectó sobre todo al ámbito relacionado con la administración de la justicia y el mantenimiento del orden público, originando una situación que daría lugar a profundas contradicciones. El campo de la promoción social por la vía de obtener privilegios militares y títulos de nobleza caería también dentro de esta área restringida. De ambos nos vamos a ocupar seguidamente.

En la remisión de penas (conmutación por otras inferiores) o en las llamadas composiciones (sustitución de la pena corporal/personal por pecuniaria) las «Instrucciones» reales restringían esta facultad tanto a los lugartenientes particulares como a los generales ${ }^{13}$; una limitación en cuya necesidad también coincidía la doctrina al valorar que su práctica podía disminuir el temor al castigo y, en ese orden, rebajar el carácter preventivo y ejemplarizante de las penas. Todo ello además de crear serios conflictos en la práctica judicial, como sucedía cuando ante los jueces se personaba un reo con salvoconducto real para declarar en una causa, teniendo pendiente una ejecución de sentencia condenatoria dictada en proceso de ausencia ${ }^{14}$. Esas dificultades se encuentran en la base de la estrecha vigilancia ejercida desde la administración central sobre los

12. LALINDE, J.: La institución virreinal.., pp. 314-320. La residencia del virrey en el territorio hacía, en teoría, más factible alcanzar de él gracias y mercedes antes que del soberano distante y ausente. Se convertía así en una facultad cuyo ejercicio era ampliamente deseado y reclamado por los gobernados, que sin embargo se opondrían al ejercicio de otras, como la legislativa, para la que se exigía la presencia del rey en Cortes.

13. Archivo de la Corona de Aragón (en adelante ACA), Consejo de Aragón (en adelante CA), Secretaría de Valencia, Leg. 620, exp. 34(3). Madrid, 20 octubre, 1664. Como recordaba el Consejo al monarca: «el privilegio de virrey de Valencia se da con latitud de cláusulas que se acostumbra, la qual puede parecer que incluye potestad de perdonar todo género de delitos. Pero para que no estén con esta inteligencia y sepan cómo se han de portar, para descargo de la real conciencia de Vuestra Magestad en estas materias se les advierte en el capítulo quarenta y quatro de la instrucción general que se da a todos, que no remitan los que fueren calificados y enormes, como son crimen de lesa magestad, plagios, resistencias, muertes acordadas, escalamientos de casas y ofender dentro dellas a los que las viven, monederos falsos, salteadores y ladrones de hurtos calificados, y que estén advertidos de que no es la real intención de Vuestra Magestad concederles facultad de perdonar lo que les está prohibido por fueros y pragmáticas».

14. Bibliteca de la Universidad de Valencia (en adelante BUV), Manuscritos (en adelante Ms.) 253, fols. 188-189, (Madrid, 21, agosto, 1632). La duda planteada por el fiscal dentro de la sala criminal motivó la 
virreyes para evitar el uso de esta potestad, que la documentación confirma. Explican, también que el Consejo de Aragón valorase como mérito sobresaliente en la gestión de los virreyes la ausencia de tales medidas de gracia durante sus ejercicios.

Paradigma de esta actitud resulta, sin duda, el matiz en la apreciación de los méritos de servicio expuestos por el Consejo de Aragón, de un lado, y el marqués de Caracena, de otro, cuando este último dirigió a Felipe III una petición de ayuda de costa para paliar las dificultades económicas que atravesaba. La hoja de servicios ${ }^{15}$ presentada en 1612 por don Luis Carrillo de Toledo, virrey de Valencia entre 1606 y 1615, recogía -por este orden-: su intervención en la reorganización del sistema penal para luchar contra el bandolerismo ${ }^{16}$; la adopción de medidas de gobierno y justicia en defensa de la regalía sobre la moneda, con el efecto de castigar a los falsificadores, retirar la moneda mala y establecer nueva ley para la misma ${ }^{17}$; y, finalmente, la puesta en práctica del sistema de arrendamiento en la gestión de los impuestos de nueva factura y en los de la ciudad (que antes habían corrido por administración) con muy buenos resultados contables ${ }^{18}$. Recordaba también «el cuidado, inteligencia y limpieza» aplicados en la expulsión de los moriscos y la colaboración prestada a la gente de guerra de los tercios de Italia, de la armada y de la milicia efectiva del reino. Se atribuía la habilidad negociadora y diplomática desplegada con los síndicos de las aljamas para propiciar la salida de los moriscos «sin la rebelión que querían hazer, de que constó por cartas que se recogieron en los caminos»; y finalizaba mencionando, sin dar detalles, sus servicios en Navarra y Galicia ${ }^{19}$. El Consejo de Aragón, por su parte, introdujo en la consulta méritos más recientes en el curriculum del virrey Caracena, tales como el arbitraje de conflictos entre el arzobispo y los canónigos o la pacificación de enfrenta-

reunión de las tres salas de la Audiencia y acabó siendo remitida a consulta del Consejo de Aragón al no llegarse a acuerdo en el tribunal valenciano.

15. ACA, CA, Secretaría de Valencia, Leg. 620, exp. 8 (2).

16. Le correspondió publicar la pragmática que en 1607 reinstauró la segunda sala civil (suprimida en 1604) dentro de la Audiencia Valencia. Por iniciativa suya se recopiló y publicó en la misma fecha la normativa relativa al funcionamiento del alto tribunal producida desde 1543 hasta finales de la centuria, con mandato expreso de leerse su contenido el segundo día de enero de cada año. Su actuación en materia de orden público y el desarrollo de su mandato en Valencia se analizan en GARCiA MARTINEZ, S.: Valencia bajo Carlos II. Bandolerismo, reivindicaciones agrarias y servicios a la monarquía, Valencia, 1991, pp. 122-133. El autor calificó como decisivo para el reino el gobierno de Caracena y destacó la dureza y eficacia de la política represiva desplegada por el virrey en el segundo y tercer trienio de su mandato.

17. Con ello había conseguido «la maior regalía que agora tiene V(uestra) M(agestad) con la diferencia de la ley de la moneda que agora se bate a la que antiguamente se batía en la Casa de la Zeca, cuyo aprovechamiento es de gran consideración para sus reales Real patrimonio», en ACA, CA, Secretaría de Valencia, Leg. 620, expd. 8(2).

18. Destacaba el hecho de financiarse con estos ingresos la guarda de la costa marítima y añadía: «sobran muchos dineros con que se podía acudir a otras cosas precisas del servicio de V(uestra) M(agestad), y en particular a la paga del servicio de las Cortes, demás de haverse puesto las Compañías de a caballo tan en orden que podrán acudir a muy grandes efectos con los arcabuzeros de a caballo que se les agregaron». En ACA, CA, Secretaría de Valencia, Leg. 620, exp. 8(2).

19. Ibidem, exp. 8(3). 
mientos entre partidarios y contrarios del venerable Simó. Pero sobre todo destacó «el cuidado, desvelo y rigor con que trata de administrar justicia, no habiendo hasta hoy perdonado a ningún delinquente, cosa nunca o pocas vezes vista en otros virreyes $»^{20}$.

La ponderación de esta circunstancia por parte del Consejo traducía las tensiones mantenidas desde la corte con las administraciones virreinales a propósito de esta materia. Los inconvenientes e irregularidades cometidos en estas actuaciones, en las que por otra parte, los virreyes no podían actuar desde su libre albedrío, sino asesorados por expertos de su curia, llevaron a prohibir las remisiones de delitos cometidos con armas de fuego mediante real pragmática de 1613 y las de delitos de bandos por real orden de $1650^{21}$. Pero la prohibición de 1613 debió tener un recorrido escaso pues ya en 1622 la facultad, retenida hasta entonces por el Consejo de Aragón, se transfería parcialmente al virrey, marqués de Tavara, en atención a la crisis de ingresos de la Tesorería valenciana $^{22}$. Diez años después se promulgaban normas para proceder en estos expedientes de manera que, en aquellos casos permitidos por ley y autorizados por el monarca, las remisiones, composiciones e indultos concedidos por el lugarteniente real o el portantveus de general governador debían contar con el acuerdo del regente de la Cancillería y del abogado fiscal, en relación al aspecto jurídico, y del lugarteniente del tesorero general, en relación a la cuantía ${ }^{23}$. Las dificultades económicas, ya fuesen en concreto de la Tesorería o en general de la Monarquía, aparecen siempre como trasfondo de estos procesos ${ }^{24}$; y lo mismo ocurre con el control y verificación de los balances de los

\section{Ibidem, exp. 8(1).}

21. Ibidem, exp. 51(2 y 3). Consultas de 16 de mayo y 15 de julio, 1679. La pragmática de 1613 retiró la facultad de remitir, componer o perdonar delitos cometidos con armas de fuego no sólo a los virreyes sino también a los magistrados inferiores que la poseían en diversos grados y a los barones con mero y mixto imperio.

22. BUV. Ms. 253, fols. 159-160. Madrid, 13, noviembre, 1622. A punto de concluir su gobierno en Valencia se autorizó a don Antonio Pimentel a conceder remisiones a los culpados por tenencia de pedernales largos, siempre que su culpabilidad no se hubiese probado plenamente.

23. Ibidem, fols. 206-209. Madrid, 11 abril, 1632. En relación a las remisiones y perdones realizados por el lugarteniente real, la intervención del abogado fiscal debía seguir las normas establecidas en el privilegio 137 de Pedro II. Para el tesorero se señalaban las pragmáticas de Carlos V de 30 de agosto de 1516 (que confirmaba la de Alfonso el Magnánimo de 1426) y 31 de agosto de 1526. En el caso del gobernador del reino se remitía a los fueros $15,16,17,18,19$ y 20 del título De poenis curiae y al privilegio 34 de Alfonso III, fol. 191, para acotar los casos en que podía operar, debiendo seguir la misma normativa que el caso del virrey en relación a la intervención del fiscal y el tesorero y dando entrada, en esta instancia, al asesor de la Gobernación que cumplía en este caso el papel asignado en la otra curia al regente de la Cancillería.

24. Aunque podrían referirse numerosos ejemplos sobre la utilidad económica de estas medidas, valgan los siguientes. En los años treinta del siglo XVII se dotó la cárcel real en Valencia de enfermería propia con médico, cirujano y boticario. La ciudad debía financiar la obra pero para la dotación de «las camas y demás adherentes a la enfermería», se ordenó al virrey, marqués de los Vélez, proponer expedientes de composición de delitos, o milicia o nobleza. Así se detalla en BUV, Ms. 253, fols. 204-205. El vicecanciller Crespí de Valldaura mantuvo una significativa relación epistolar con el virrey Camarasa para instruirle en el reparto de ingresos procedentes de remisiones y composiciones. En aquel momento el $20 \%$ de la recaudación era detraída por la corona para fines particulares y el resto de las cantidades ingresadas 
lugartenientes del tesorero, como demuestra la revisión de la gestión de don Ramón Sanz de la Llosa en $1622^{25}$ o la de don Pedro de Borja en $1654^{26}$.

Administrar la gracia real entre las presiones derivadas de las urgencias económicas y las necesidades del orden público requería sutileza y tacto político y, aún así, no dejaba de ser un asunto problemático. Desde luego a ninguno de los virreyes valencianos del Seiscientos se les autorizó de entrada, como indicaba antes, a ejercer medidas de gracia sobre los delitos «exceptuados» (bandos y armas de fuego). Las concesiones requirieron siempre la petición previa de los lugartenientes reales y fueron motivo de debate dentro del Consejo de Aragón. Para sus miembros, ceder a las peticiones virreinales en este sentido acabó convirtiéndose en un mal menor, que volvió habitual la transgresión de la prohibición de remitir, componer o indultar tales delitos ${ }^{27}$. La conversión de la excepción en norma queda acreditada por la concesión de permiso para actuar esta gracia a los virreyes Oropesa, Montalto, Camarasa y San Román, además de al arzobispo fray Pedro de Urbina y al gobernador don Basilio de Castellví en sus respectivos períodos de interinidad vicerregia y, en el caso de este último, en calidad también de capitán general ${ }^{28}$. La situación descrita, que recorre grosso modo los últimos 20 años del reinado de Felipe IV, parecía dar visos de normalidad a la que hasta entonces había sido una excepción. Así continuó en la época de Carlos II; por ello el duque de Veragua la reclamaba aún antes de entrar en el ejercicio como virrey

se repartían entre las personas y efectos que correspondiera. En ARV, RC, Epistolarum, Reg. 590, fols. 336r. ${ }^{\circ}-337 r^{\circ}$ y 350v. ${ }^{\circ}-351 r^{\circ}{ }^{\circ}$ Madrid, 1660-1661)

25. ARV, RC, Epistolarum, Reg. 590, fols. 147-159. San Lorenzo, 8 de octubre, 1622. Documento de gran interés por detallar la naturaleza de las partidas contables de la Tesorería valenciana, la intervención de diferentes oficiales y ministros con cuya gestión se construye el balance contable de la institución y los diferentes conceptos que constituyen los capítulos de ingresos y gastos de la misma.

26. ARV, RC, Epistolarum, Reg. 590, ff. 214r. ${ }^{\circ}-215$ v. $^{\circ}$ : Resolución de algunas dudas que hubo en las cuentas de D. Pedro de Borja, lugarteniente de Tesorero. Madrid, 2 de julio, 1657.

27. ACA, CA, Secretaría de Valencia, Leg. 620, exp. 51(2). Consulta de 16 de mayo, 1679. Al solicitar para sí el duque de Veragua esta facultad, el Consejo señaló a Carlos II: «si hubiese medios para acudir a estos gastos (los de la Tesorería) sin hazer remisiones de delitos, era practicable negar esta facultad al virrey. Pero no habiéndolos (como no los hay) en concurso de dos incombenientes es mucho menor el de conceder algunas gracias (de cuya facultad los virreyes prudentes usan con templanza que no perjudique al bien público) que no el dexar de acudir a las diligencias de la administración de la justicia y castigo de los mismos delinquentes, los quales en conociendo omisión o flaquezas por esta parte cobran avilantez y se precipitan a mayores atrocidades, persuadiéndose a que no van a ser castigados».

28. ARV, RC, Epistolarum, Reg. 590, fols, 69 v. ${ }^{\circ}-72$ r. $^{\circ}$, sobre Oropesa; fols. 118 r. $^{\circ}$ y 123 v. ${ }^{\circ}$, para la facultad concedida al duque de Montalto en relación a los delitos de bandos (agosto, 1654) y «escopetazos» (octubre, 1654); fols. 260 r. ${ }^{\circ}-{ }^{\circ} .^{\circ}$, autorización al virrey Camarasa en relación a ambos tipos delictivos (julio, 1659); fols. 432r. ${ }^{\circ}-434 \mathrm{v}^{\circ}$, autorización al virrey San Román para perdonar delitos cometidos con armas de fuego (diciembre, 1664) y de bandos (enero, 1665); fol. 337r. ${ }^{\circ}$, ordenando a Camarasa expedir despachos de perdones realizados por fray Pedro de Urbina al no haberse sacado en su momento (Madrid, agosto, 1660); fols. 423v. ${ }^{\circ}-434 \mathrm{r}^{\circ}$, indicando a don Basilio de Castellví el estilo que debe seguir en las remisiones de delitos concedidas por el tribunal de la Capitanía general (febrero, 1664). 
de Valencia en 1679, y el monarca se la concedió al igual que a su sucesor en el cargo, conde de Aguilar, y antes que a ellos al conde de Paredes ${ }^{29}$.

La autorización de esta facultad en los virreyes solía darse tras los primeros años de ejercicio y cubría la duración del mandato. Normalmente se justificaba por parte del rey con argumentos como la «recitud y zelo de la justicia con que procedéis en vuestro gobierno y a la satisfacción con que me hallo de vuestra persona»; o aludiendo a «la conveniencia pública y buena política ${ }^{30}$. Siempre se ordenaba al alter ego ejercerla con moderación y prudencia, objetivo no siempre conseguido pues los representantes regios solían hacer un uso abusivo de esta facultad en su propio beneficio, sobre todo en las postrimerías de sus mandatos. Esa observación sería enfatizada por el Consejo de Aragón a propósito de un informe del virrey marqués de San Román sobre sus predecesores en el cargo (Montalto y Camarasa). En la apreciación del Consejo se indicaba:

se experimenta que a la salida exceden no mirando el reyno que dexan como quando corre por su cuenta el gobierno, y así a la salida de entrambos (Montalto y Camarasa) concedieron muchas remisiones que devieran haverse excusado y, demás de ser algunas dellas de casos muy graves y en descrédito de la justicia, no las hicieron con la formalidad que las pragmáticas y reales órdenes disponen, aplicando a su voluntad parte de lo procedido dellas que es grave inconveniente y muy mal exemplar ${ }^{31}$.

Desde luego utilizar el expediente de la gracia, perdonando a miembros de bandos, tenedores de armas prohibidas, delitos cometidos con aquellas, etc, significaba poco menos que combatir el fuego con fuego y así lo entendían tanto los ministros de la corte como los propios virreyes. Don Antonio Pedro Álvarez-Osorio, marqués de San Román, había criticado abiertamente el comportamiento en este sentido de su predecesor, el virrey Camarasa ${ }^{32}$ y se ufanaba de haber conseguido erradicar las parcialidades y puesto en fuga al bandolero Josep Artús y su cuadrilla con su política de rigurosos castigos y ausencia de medidas de gracia. Pero ello no le impidió solicitar, apenas unos meses después de tan solemne declaración, la correspondiente licencia para perdonar él también delitos de armas de fuego ${ }^{33}$. Los argumentos esgrimidos por San Román para justificar su cambio de actitud planteaban la medida como un refuerzo de cara a la

29. ARV, RC, Epistolarum Reg. 591, fols. 130v. ${ }^{\circ}$ (Madrid, 28 junio, 1679) y 159r. ${ }^{\circ}$ (Madrid, 24 septiembre, 1680). Consta igualmente la concesión al conde de Paredes en 1668, Ibidem, fol. 39r. ${ }^{\circ}-\mathrm{v}^{\circ}{ }^{\circ}$

30. Ibidem, Reg. 590, fols. 118 r. $^{\circ}$ y 260r. ${ }^{\circ}-{ }^{\circ}{ }^{\circ}$ y ACA, CA, Secretaría de Valencia, Leg. 620, exp. 34(7).

31. ACA, CA, Secretaría de Valencia, Leg. 620, exp. 34(3). Consulta de 20 de octubre, 1664.

32. Ibidem: «escribe el marqués de San Román a Vuestra Magestad los graves inconvenientes que se siguen de las remisiones de delitos, pues muchas vezes por no castigar a uno se inquieta todo un lugar y resultan homicidios y bandos que no son fáciles de ataxar después, por cuias consideraciones diçe el marqués que, en el sentir de los ministros y de sus antecesores, el cerrar las puertas al perdón por todas partes, asentado por proposición fixa que en ninguno se ha de dispensar, de suerte que no quede camino ni resquicio a la esperanza, es el único remedio para ataxar esta horrible costumbre de delinquir tan embegecida en el reyno, y representa otras muchas consideraciones muy justas y conforme a razón y buena política para que se excuse el conceder perdones». (Consulta de 20 de octubre, 1664).

33. Ibidem, exp. 34(4). Consulta de 11 de noviembre, 1664. 
opinión pública del aprecio del rey hacia su gestión («lo que en este reyno he obrado... se ha debido principalmente al lustre y resplandores con que entré..de favorecido de Vuestra Magestad...y el mantenerse este concepto haze adelantar los buenos sucesos de mi govierno); también como una equiparación de funciones con sus predecesores (averlo conseguido mis antecesores y dejarme a mí sin lo que todos tuvieron fuera singularidad muy notable»); y, finalmente, como complemento de su acción de gobierno, en la que al castigo debía seguir el premio:

el tener esta ampliación conduce al buen gobierno para que estén pendientes los ánimos de todos al arbitrio de el virrey, pues no mirándole con esta potestad, podrán temerle para el castigo, más no asistirle a negocios y servicios que se offrezcan del de Vuestra Magestad con aquella eficacia a que obliga la esperanza de que les puede valer en caso de necesidad.

Las dos caras del balance quedaban claramente reflejadas en el desarrollo de la situación descrita. Recogían el dilema en que se veían envueltos soberano y Consejo a cada paso; dilema que conducía a una acusada falta de criterio a la hora de tomar decisiones, definidas sobre expectativas de futuro que no siempre se cumplían ${ }^{34}$. La única voz discrepante en este panorama acomodaticio y pragmático fue la del regente del Supremo Juan Francisco Fernández de Heredia en la tardía fecha de 1678. Este letrado se opuso con argumentos de forma y fondo a la petición elevada por el lugarteniente de la Tesorería y consejero de capa y espada de la Audiencia valenciana, don Alonso Milán de Aragón. Solicitaba, a la vista de la falta de medios para acudir a la administración de la justicia, se concediesen al arzobispo y virrey interino, fray Juan Tomas de Rocabertí, licencias para librar a la Tesorería efectos por vía de expedientes secretos y para hacer remisiones de delitos cometidos con armas prohibidas. Fernández de Heredia censuró la usurpación por el tesorero de una función que correspondía al virrey (solicitar recursos para hacer frente a las necesidades financieras); pero sobre todo puso el acento en la contradicción de efectos entre la gracia demandada y el objetivo final de la administración de la justicia y el buen gobierno.

Frente a la actitud en principio conformista del resto del Consejo ${ }^{35}$, el regente discrepante volvía a recordar, a más de una década de distancia, los consabidos abusos cometidos por los virreyes en la aplicación de estas medidas. Su prodigalidad y arbitrariedad en el uso de tales gracias llegaba, en su versión, a provocar rechazo en la misma sociedad que las acogía («es notorio haciendo tantos perdones dexan desconsolado el reyno de Valencia»). Y reafirmaba el descrédito de la justicia por esta vía pues, en su

34. El virrey San Román no sólo obtuvo su propósito inicial sino que consiguió la ampliación de la licencia a los delitos de bandos. En ACA, CA, Secretaría de Valencia, Leg. 620, exp. 34(1 y 5). Consultas de 22 noviembre, 1664 y 16 diciembre, 1665.

35. ACA, CA, Secretaría de Valencia, Leg. 620, exp. 51(3). Consulta de 15 de julio, 1678.: «Y sin que destas remisiones se pueda esperar que fructifiquen para ocurrir a las necesidades públicas habiendo experimentado el Consejo que no se consigue ni se saca lo bastante para pagar lo más preciso que aquella Thesoreria tiene sobre sí de cargas, siendo constante que sin embargo de haver concedido esta facultad a otros virreyes, Vuestra Magestad ha socorrido por medio del Consejo de otros efectos la misma Thesoreria con cantidades muy considerables». 
consideración, condonar graciosamente los delitos constituía un exceso y, «si media género de multa o dinero (que no se puede creer), son en gran dispendio de la justicia, desagradable a Dios, incentibo de otras atrocidades y que se desempeñen a delinquir más, pues con facilidad han de componer sus delictos por dinero». Sus argumentos modificaron la opinión del Consejo en pleno que acabó recomendando al rey mantener la limitación impuesta a los virreyes en la administración de la gracia y obligarles a enviar a la corte los casos que hubiese que considerar. Las autorizaciones luego concedidas a los virreyes duque de Veragua ${ }^{36}$ y conde de Aguilar demuestran, no obstante, una nueva quiebra del criterio. Pero en cualquier caso, la toma de postura del Consejo denotaba una fuerte concienciación de la problemática implícita en la administración de la gracia, sujeta, en mayor medida si cabe que la de la justicia, al arbitrio de quien la dispensaba.

De otro lado, la concesión de títulos nobiliarios y privilegios militares fue una medida de gracia no sólo negada en la práctica a los virreyes, sino incluso parcamente administrada por los monarcas, quienes sólo en caso de necesidad y previa compensación económica o como recompensa política comenzaron a hacer un uso pródigo de la misma en el XVII ${ }^{37}$. En estas materias, los virreyes se limitaban a proponer los sujetos a quienes agraciar con privilegio militar o título, a asesorar a la corte sobre las peticiones formuladas $y$, en último término, a investir a los nuevos caballeros y nobles una vez alcanzada la gracia real. Un ejemplo significativo de la que parece ser máxima participación de virrey y su entorno curial en este tipo de concesiones graciosas la encontramos reflejada en la solicitud de privilegio de hidalguía y prerrogativa militar cursada por los notarios de Valencia a Carlos II en 1682. El monarca, atendiendo la cuantía del donativo (3000 doblones) ofrecido por los peticionarios, solicitó informe al virrey, conde de Aguilar y Frigiliana, quien a su vez reunió para dictarlo a las tres salas de la Audiencia ${ }^{38}$. A la vista de los inconvenientes derivados de los privilegios jurisdiccionales en vía civil y criminal y las exenciones fiscales que pasarían a disfrutar, así como el elevado número de los existentes en la capital y reino y su ritmo de creación, la procedencia social y la misma diferenciación interna dentro de este grupo profesional y la naturaleza de su ejercicio, se informó negativamente la petición. Para mayor refuerzo de los argumentos expresados, el órgano asesor indicaba:

Que este reyno se ha conservado con la diferencia de nobles, cavalleros, ciudadanos y plebeyos. Los privilegios de los primeros no pareze razón participarles al pueblo y más con tanta generalidad como la súplica contiene de un gremio entero...De ver los cavalleros

36. Volvió a dar lugar a la presentación de voto particular del mismo regente en la consulta de mayo, 1679. En ACA, CA, Secretaría de Valencia, leg. 620, exp. 51(2).

37. Pastor i Fluixa, J.: «Nobles i cavallers al País Valènciá», en Saitabi, XLIII. Homenatge al profesor en Jaume Pastor i Fluixá, València, 1993, pp. 1-54 y CANET, T., «Los apuros del rey» en Estudis. Revista de Historia Moderna, 24 (1998), pp. 185-202. El papel de los representantes regios en esta materia se limitaba, en la práctica, al acto de armar caballeros y a la presentación de los candidatos más idóneos para recibir la gracia del título o privilegio militar.

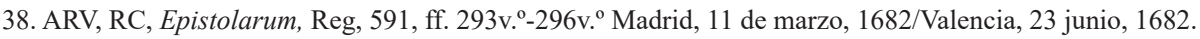


comunicados sus privilegios a tantos hombres inferiores, sin lustre ni decencia, seguiría gran desconsuelo, motivo que solo bastaría para no conceder la gracia que se suplica, como también que habiéndola hecho (la misma petición) en diferentes ocasiones, siempre se les ha negado ${ }^{39}$.

Siguiendo la recomendación indicada, Carlos II denegó la gracia e impuso al Colegio de Notarios silencio perpetuo sobre el particular.

Convendrá recordar, al hilo de la materia expuesta, que las mercedes honoríficas, pese a recaer en el campo de la jurisdicción voluntaria, podían entrañar cuestiones legales que era necesario resolver. Abarcaban, además, un amplio abanico de situaciones que iban desde una inicial declaración de ciudadanía hasta la transmisión de títulos dentro o fuera de una misma familia. Y, en la medida en que estos expedientes pasaron a ser utilizados por la corona como fuente de ingresos económicos, se tendió a establecer sobre ellos un estricto control. Así, desde los años veinte del siglo XVII se dictaron medidas administrativas para depurar el acceso a la milicia y se tendió a centralizar en la Audiencia-tribunal los procedimientos de esta índole. Esa vía, sumada al asesoramiento de la Audiencia-Consejo en materia de honores, reforzó el ascendiente del entorno curial del virreinato en el ejercicio contenido de esta potestad.

El celo demostrado por la monarquía en orden a la administración de la gracia por los virreyes contradice, al tiempo que explica, el sentido y la función de los consejeros de capa y espada en estas materias. La contradicción queda reflejada en el hecho de asociar un mayor número de oficiales para la actuación de una función cuyo ejercicio se limita -cuando no se prohíbe- de forma reiterada. La explicación podría encontrarse en la necesidad de moderar la arbitrariedad en ejercicios tan controvertidos, cuando se autorizaban, con la finalidad de objetivarlos de la manera más amplia posible. Ese doble juego de sentidos parece encajar bien en relación a la concesión de licencias para remitir, componer o perdonar delitos; no tanto en la dispensa de privilegios y títulos nobiliarios en cuya dinámica no intervenía de forma tan activa la persona del virrey. Dispensar gracia en materia penal no dejaba de ser un reflejo del arbitrio regio, pero arropada con deliberaciones en torno a la oportunidad, conveniencia y utilidad puntual de la acción en las que intervenían juristas y militares, restaba protagonismo a la figura del alter ego y revestía de consenso la acción.

\section{ACTUAR EL GOBIERNO DEL REINO: UN EJERCICIO CONFLICTIVO}

El ejercicio de la potestad administrativa o de gobierno ${ }^{40}$ se traducía en actuaciones tendentes al mantenimiento del orden público, uso y tenencia de armas, regulación de asociaciones y reuniones, provisión de oficios, competencias en materia de economía (abastos y comercio interior, acuñación de moneda, cambios), hacienda y patrimonio (fundamentalmente desde la presidencia de la Junta Patrimonial), sanidad, beneficencia, obras públicas, licencias y privilegios de impresión. La influencia de los

39. Ibidem, Reg. 591 , f. $295 \mathrm{v}^{\circ}$

40. LaLINDE, J.: La institución virreinal..., pp. 331-381. 
virreyes en el ámbito municipal era notable, siendo de destacar la facultad de conceder imposiciones de sisas o la intervención indirecta en las insaculaciones, depurando listas. El carácter privado de la enseñanza y el régimen autónomo de las universidades situaban este ámbito fuera de las competencias de los lugartenientes del rey, salvo por motivos de orden público. Recaía, sin embargo, en la autoridad virreinal la concesión de salvaguarda especial a catedráticos, maestros, estudiantes, bedeles y demás personal, además de a sus familiares. Informaban algunas provisiones de cátedras y aunque en el privilegio se les confería capacidad para crear notarios reales, cirujanos, médicos y doctores en derecho, en las instrucciones se les limitó de ordinario esta atribución. En su calidad de alter nos, correspondía a los virreyes asumir la defensa del territorio y, como capitanes generales, dirigían la guerra y ejercían jurisdicción sobre los soldados o estipendiarios. En relación a la concesión de guiatges y salvoconductos, antes mencionada, la facultad otorgada al virrey era mucho más amplia que la disfrutada por otras instancias también facultadas para concederlos.

En el ejercicio de esta potestad de gobierno, amplísima por el diverso contenido de actuaciones que recogía, el lugarteniente real contaba con el asesoramiento de la Audiencia y Consejo. Y lo hacía, como veremos, en una medida mayor que en la dispensación de gracias, simplemente porque en este campo de actuaciones la intervención de virrey y Consejo sí se reclamaba de manera real y efectiva. Por ello mismo y por las especiales circunstancias internas del reino de Valencia en el Seiscientos, la documentación se muestra algo más generosa que en el tema de la gracia a la hora de reflejar las actuaciones de la Audiencia en función consultiva. Sin duda se debe, también, a la puesta en marcha del registro de las llamadas «Cartas acordadas», comentada anteriormente, pero, en cualquier caso, nos sirve para comprobar la participación de los consejeros de capa y espada de la sala criminal de la Audiencia en esta actividad del órgano. Algunos ejemplos significativos bastarán para ratificar esta situación, teniendo siempre en cuenta que ni todos los hechos registrados tuvieron la misma entidad, ni se resolvieron con criterios unánimes, ni, por supuesto, se sustanciaron de manera definitiva en el seno del Consejo valenciano.

El plenario de la Audiencia - es decir, las tres salas de la institución-era convocado para asuntos de gobierno tan dispares como la realización de informes sobre medios para acabar con los receptadores de cuadrillas de bandoleros ${ }^{41}$, contestar peticiones de exención de costas en sentencias de contención ${ }^{42}$ o para determinar la viabilidad de nuevas fundaciones religiosas ${ }^{43}$. Además, en los primeros años de gobierno del virrey Montalto, la tirantez alcanzada en las relaciones con los estamentos a propósito del

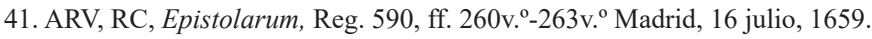

42. Como ocurrió con el pavorde y cabildo de Orihuela. Ibidem, ff. 68 r. $^{\circ}-69$ r. ${ }^{\circ}$ Real de Valencia, 11 noviembre, 1653.

43. ARV, RC, Epistolarum, Reg. 590, ff. 288v. ${ }^{\circ}-290$ r. $^{\circ}$, recoge El virrey el informe enviado a Madrid por el virrey Camarasa sobre la funación del convento de monjas dominicas que pretendía Jacinta Sabater. Acreditaba su viabilidad avalado por la consulta celebrada con la Audiencia. Real de Valencia, 11 de marzo, 1659. 
servicio solicitado en 1653 para atender la guerra en Cataluña ${ }^{44}$ dio lugar a intensas y prolongadas sesiones deliberativas del virrey con la Junta por él creada a este efecto y de la que formaban parte casi todos los miembros de la Audiencia y Consejo ${ }^{45}$. Esas mismas tensiones desembocaron en una acentuada atención del virrey hacia el gobierno de la capital, que disimula mal sus intentos de control de la oligarquía capitalina.

En esa línea, se sitúa la impugnación por el virrey de la elección de jurados de 1653, argumentando su realización fuera de plazo. Con la finalidad de acertar en el procedimiento a seguir recabó el asesoramiento de las tres salas de la Audiencia ${ }^{46}$. Unos años después denunciaba una práctica en la política municipal que, a su juicio, constituía un flagrante fraude de ley. La cuestión que el lugarteniente real planteó al rey y su Consejo Supremo partió de su iniciativa personal pero, según su propio testimonio, para desarrollarla «convocó junta de ministros» ${ }^{47}$, en referencia a las salas de la Audiencia. El problema denunciado por el virrey se planteaba en los términos siguientes. La legislación vigente impedía concurrir a las elecciones para jurados a quienes ejercían oficios perpetuos en el municipio. Moncada venía observando que esta norma era burlada mediante un ardid singular. Uno o dos días antes de las elecciones los aspirantes renunciaban los cargos; de no salir en la suerte, los volvían a ocupar, y si eran elegidos dejaban el ejercicio del cargo en manos de algún pariente o amigo para volverlo a recuperar al expirar el año de juraduría. Al fraude descrito se añadía, desde la percepción del virrey, la necesidad de depurar las listas de aspirantes procurando, «por toda razón política, que de los insaculados no concurran en los officios de jurados los que son menos atentos al servicio de V(uestra) M(agestad) y más opuestos a la quietud y sosiego de la Ciudad, pues sus materias necesitan más personas que las quieten que no de sujetos que las turben».

En esa tesis, el virrey entregó a los convocados la lista de los que a su juicio debían ser excluidos de la elección de jurados por inadecuados o impedidos por ley y les solicitó opinión sobre forma y medios para proceder contra ellos. Entre los vetados figuraban Sebastián Pertusa Bonastre, miembro de la embajada que recientemente había visitado la corte acompañando al jurado Juan Llorens, y Grisógono Almela, «uno de los fomentadores de dicha jornada y de las resoluciones que en su progreso se han hecho». Para el virrey, ambos se preciaban de tener mucha práctica en las lides negociadoras, pero, en realidad -sentenciaba-, «encaminan sus decisiones a parecerlo y no tienen atención alguna hacia el real servicio ni la quietud pública». Todo ello además de estar impedidos para concurrir en la insaculación dada su condición de administradores de las sisas de la ciudad, un cargo otorgado a perpetuidad. Los ministros reunidos en junta apoyaron la iniciativa del lugarteniente real, pero recomendaron se solicitara

44. GuiA, L.: «Los estamentos valencianos y el duque de Montalto: los inicios de la reacción foral», en Estudis. Revista de Historia Moderna, 4 (1975), pp. 129-145, para un desarrollo amplio de este episodio.

45. ARV, RC, Epistolarum, Reg. 590, ff. $28 v^{\circ}{ }^{\circ}-35 r^{\circ}{ }^{\circ}$ Los problemas de orden diverso que en ella se plantearon la mantuvieron en sesión varios meses.

46. Ibidem, ff. 40r. ${ }^{\circ}-45 \mathrm{r}^{\circ}{ }^{\text {Valencia, } 3} 3$ junio, 1653.

47. Ibidem, ff. 204r. ${ }^{\circ}-207$ v. $^{\circ}$ Valencia, 27 marzo, 1657. 
del propio monarca una nueva declaración de incompatibilidades en el sentido señalado. El acuerdo se trasladó a la corte donde fue ratificado y comunicado a los munícipes capitalinos. Las observaciones aportadas por la ciudad en torno al carácter amovible de los titulares de las administraciones de sisas - que pretendía en último término preservar la intención de los afectados- sólo sirvió para introducir más precisiones en el decreto virreinal. Y, en último término, para hacer salir al jurado Llorens, por orden real, de las bolsas de insaculación ${ }^{48}$.

El asesoramiento de la Audiencia y Consejo en la potestad de gobierno de los virreyes no significaba necesariamente coincidencia y consenso entre todas las instancias implicadas. Así se manifestó con ocasión de la pretendida desobediencia de la ciudad durante el acto de traslado de la Bula de Cruzada ${ }^{49}$ a la iglesia catedral. A la procesión celebrada al efecto habían sido convocadas las autoridades municipales. La ausencia del racional y el síndico en dicho acto, así como la de los jurados en el ofício religioso del día siguiente, se achacaron a una cuestión de precedencia que privilegiaba en estas funciones al lugarteniente de tesorero de la Cruzada frente al contable de la ciudad y su síndico. Como el orden procesional se había establecido siguiendo una disposición regia (real carta de 25 de abril, 1655), Montalto interpretó el gesto como desobediencia institucional que, al no ser corregida tras una primera reconvención del virrey, le movió a reunir a las tres salas de la Audiencia y Consejo.

En la versión del duque-virrey, «sintieron unánimemente los ministros ser inobediencia que no podía disimularse». Se resolvió prender al síndico por haber incumplido el mandato virreinal de personarse en la iglesia y trasmitir la orden de aquel a los jurados. Sería conducido a las Torres de Serranos y si acaso pedía la Diputación por cárcel, se le daría pero «con fiadores, según forma de fuero». Las diligencias previas a la detención se encargaron al doctor Gaspar Salvador, de la sala criminal. Sus indagaciones pusieron en claro que el síndico sí había transmitido a los jurados y racional la orden del virrey, pero la indisposición por enfermedad de unos y el retraso en la llegada de otros al lugar donde se habían citado para acudir corporativamente les situaron a las puertas de la iglesia cuando estas ya estaban cerradas. Un acta notarial registrando los hechos referidos, avalaba la declaración del síndico.

Para el juez, esta evolución de acontecimientos eximía al síndico del cargo de desobediencia y reducía el lance a una grave descortesía. Comunicó los hechos a algunos ministros «en sus casas» y decidieron aceptar las disculpas y suspender la prisión, evitando de esta manera un nuevo encontronazo con la ciudad. Tratado el tema al día siguiente en el plenario de las salas, el regente don Antonio Juan de Centelles, y los doctores Gombau, Esteve, Matheu y Sanz y De la Torre discreparon abiertamente. Hallaban incumplimiento de funciones en el síndico por no haber comunicado con antelación suficiente la orden del virrey; veían premeditación en la acción del gobierno

48. Ibidem, ff. 205v. ${ }^{\circ}-207 v .^{\circ}$ Correspondencia entre Madrid y Valencia, abril-junio, 1657.

49. En expresión del virrey, «gracia del Pontífice», por lo que la descortesía de autoridades y oficiales municipales en este suceso agravaba la conducta. Su desarrollo en ARV, RC. Epistolarum, Reg. 590, ff. 224 r. $^{\circ}-228$ r. $^{\circ}$ Valencia, 29 enero, 1658- Madrid, 16 febrero, 1658. 
municipal y consideraban que las explicaciones aportadas por el representante municipal no resistían la más mínima crítica. La prisión del síndico debía ejecutarse, a su criterio, y llegar hasta las últimas consecuencias en este suceso. Montalto se encontró, así, ante una división de opiniones y posturas que obligó a elevar consulta al rey. La resolución dictada comprendía tanto una reprensión severa a los munícipes por su efectiva desobediencia de la real orden, como la advertencia de «demostración conveniente» si se reproducían los hechos. El suceso había puesto en claro el celo del alter ego; pero también la diferente disposición a la contemporización dentro del Consejo real valenciano, donde la postura de los letrados había sido manifiestamente más dura que la de los militares.

Las relaciones con la Inquisición local constituyen otra materia singular, tanto en el aspecto contencioso, que no es de nuestro interés ahora, como en el de las familiaturas cuyo control entraba en el campo de la acción de gobierno de los virreyes. La materia, como veremos, mantiene una estrecha conexión con las cuestiones de justicia y orden público. Y remite, necesariamente, a las relaciones de los gobiernos establecidos con los grupos privilegiados en distintos campos.

Uno de los episodios con mayor eco en la documentación acaeció durante el mandato del virrey Montalto. A este noble italiano parece llamarle poderosamente la atención el tema de las familiaturas en Valencia por contraste con la experiencia vivida en Cerdeña y Sicilia. A la vista del número de los que él calificaba como «familiares poderosos» (miembros de la nobleza local), se planteó como objetivo de gobierno acabar con tal estado de cosas mediante el cumplimiento estricto de las Concordias y reales órdenes vigentes. La iniciativa en este asunto fue personal del virrey, pero el desarrollo de la cuestión y, sobre todo, la ejecución de la real orden expresada al término de la exposición del caso que referiremos por paradigmático, obligó a reunir y debatir con el pleno de la Audiencia las incidencias y resoluciones que se fueron adoptando.

El suceso que promovió la acción virreinal en la materia fue la concesión de familiatura inquisitorial a don Felipe Boïl de la Scala, barón de Manises, y a don Giner Rabaça de Perellós, barón de Dos Aguas en $1657^{50}$. Pasaban con ello a engrosar la lista de nobles-familiares en la que ya figuraban el conde de Casal, el barón de Náquera, el conde de Parcent o el barón de Alcalalí. Montalto denunció entonces el incumplimiento de las reales cartas de 11 de mayo de 1554 y 17 de julio de 1568 que instaban a observar las Concordias firmadas entre las jurisdicciones real e inquisitorial que insistían, entre otros extremos, en la prohibición de otorgar familiatura a caballeros y barones. Fallos de contenciosos dictados por inobservancia de estas disposiciones eran también reseñados por el virrey para reforzar su postura. Así traía a término la anulación de nombramientos recayentes en señores de vasallos de la época de Aitona (1590), decidida por los Consejos de Aragón e Inquisición; la negativa de declinatoria de fuero solicitada por don Francisco Milán de Aragón, barón de Otos, en la causa civil mantenida con don Carlos de Equila, que el primero pretendía por ser familiar del Santo

50. ARV, RC, Epistolarum, Reg. 590, ff. 208v. ${ }^{\circ}-212$ r. $^{\circ}$ Valencia, 28 mayo, 1657. Madrid, 2 julio, 1657. 
Oficio, pronunciada en la misma instancia que el caso anterior; o, más recientemente, el fallido intento de liberar al marqués de Rafal de la prisión contra él decretada por Montalto, en el que los inquisidores quisieron hacer valer, sin éxito, el argumento de su familiatura y que había sido fallada en la instancia regnícola.

Los argumentos esgrimidos por Montalto en este tema se relacionaban con los efectos de la situación aludida sobre la administración de justicia y sobre los servicios solicitados por la corona a los estamentos. En el primer caso, el aforamiento de los familiares sustraía a los nobles de la jurisdicción real y facilitaba la impunidad de aquellos, «pues para ejercerla en las personas poderosas se instituyeron los tribunales de las Audiencias reales donde presiden los lugartenientes de V(uestra) M(agestad), cuia auctoridad y dependencia las reprime a vista de que sin excepción alguna son castigados todos condignamente». Este alcance universal de la justicia no se cumplía, según el virrey, en el tribunal inquisitorial dado que la condición eclesiástica de sus miembros les impedía ejecutar penas capitales y dejaba impunes graves delitos cometidos por miembros del estamento militar ${ }^{51}$. Montalto se sorprendía por la facilidad con que en Valencia, al contrario de otros reinos, los inquisidores se inmiscuían en el conocimiento de delitos graves, de cuyo conocimiento se abstenían en general los eclesiásticos por no poder «condemnar en penas condignas, que es el único medio de conservar la república».

Otro inconveniente derivado de la situación existente afectaba a los servicios solicitados a los estamentos dentro o fuera de Cortes. Para el virrey resultaba más fácil orientar las voluntades de quienes estuvieren sujetos a la jurisdicción real que de los que estaban exentos de ella «en sus causas», matizaba. Para Montalto el número de exentos en el reino era significativo teniendo en cuenta el aforamiento especial de religiosos y clérigos, beneficiados, tonsurados y caballeros de Montesa y de otras órdenes militares.. Si a todos estos se sumaban ahora los familiares de la Inquisición pertenecientes a la nobleza, «no habrá -señalaba el virrey- persona poderosa en el reyno que no sea exempta con gran perjuicio de la quietud pública y no poca desauctoridad de los virreyes, real Audiencia y demás ministros de V(uestra) M(agestad) que apenas tendrán jurisdicción en persona alguna que suponga algo o sea de calidad, siguiéndose dello la falta de beneración que es tan devida a los tribunales maiores $»^{52}$.

La proliferación de familiaturas de esta naturaleza no era, desde luego, una novedad, según denunciaba el virrey. Por ello mismo, los inquisidores argüían «la costumbre» en defensa de esta práctica, mientras que el virrey pretendía acabar con ella para evitar «fijar más su derecho de posesión» y exigía, de entrada, que se cumpliera el capítulo 3. ${ }^{\circ}$ de la Concordia de 1554 que obligaba a los inquisidores a notificar al lugarteniente real las listas de familiares de la ciudad de Valencia, y a los gobernadores y justicias locales las de los lugares del reino. Esta norma jamás cumplida, según Montalto,

51. Ibidem, f. 210 r. $^{\circ}$ : «nunca llegan los delictos graves a punirse con la pena devida, siendo así que en casos capitales jamás se extiende, ni puede, a pena de muerte y la maior es la relaxación al brazo, que tan raras veçes se ha visto practicada».

52. Ibidem, ff. $210 \mathrm{v}^{\mathrm{o}}-211 \mathrm{r}^{\mathrm{o}}$ 
había propiciado la proliferación incontrolada de familiaturas ahora denunciada. La respuesta de Felipe IV -entre el cansancio por la obligada reiteración de disposiciones acatadas pero no cumplidas y la desesperación por la excesiva meticulosidad política de don Luis de Moncada ${ }^{53}$ - no podía ser otra que ordenarle poner los medios para hacer cumplir la disposiciones vigentes.

Precisamente las derivaciones del tema planteado nos introducen en un campo altamente sensible en la Valencia del XVII. Se trata del ejercicio de la «económica» por parte de los virreyes. Esta materia ha merecido un tratamiento monográfico por mi parte en otro trabajo ${ }^{54}$, por lo que me limitaré a señalar con brevedad las conclusiones más relevantes. En ese orden cabe destacar que este ejercicio, en el XVII, fue actuado siempre con asesoramiento y concurso de la sala criminal (ministros de capa y espada, incluidos), que no admitía en su aplicación excepción de personas o fuero y que se convirtió, sin duda alguna, en un instrumento de disciplinamiento especialmente activo sobre la nobleza local.

\section{AMPLIACIÓN DEL CONSENSO Y EQUILIBRIO DEL ARBITRIO POLÍTICO}

De manera inexcusable, la investigación de las funciones desempeñadas por los consejeros de capa y espada nos ha situado en los entresijos del gobierno virreinal en la segunda mitad del Seiscientos valenciano. La creación de las plazas en cuestión no parece haber modificado de manera llamativa el ejercicio de las potestades virreinales o los cometidos de la Audiencia, institución en cuyo marco se insertaron estos nuevos puestos. Sin embargo, la ampliación del órgano asesor por esta vía reforzó la naturaleza de la Audiencia como Consejo consultivo y, en ese orden, la aproximaría más en su perfil funcional al Consejo Supremo de Aragón, toda vez que para ambas instancias la presencia de consejeros no letrados desde mediados del XVII significara una modificación de su naturaleza original. Desde esa dimensión de la Audiencia como órgano asesor, la presencia de miembros de la nobleza local representó la ampliación de las voces que debían intervenir en la construcción del consenso a la hora de definir cuestiones no contenciosas.

Por otro lado, aunque el ejercicio de la gracia siguió estando estrictamente bajo control del soberano y su Consejo Supremo, la facultad de remitir determinados delitos y conmutar ciertas penas - puntual, pero invariablemente reconocida a los virreyes desde los años cincuenta (coincidiendo precisamente con la activación de las plazas de capa y espada)-, permite establecer cierta relación entre ambos procesos. La andadura conjunta de las dos tendencias induce a interpretar la medida como un elemento

53. Ibidem, ff. $211 \mathrm{v} .^{\circ}-212$ r. $^{\circ}$ Madrid, 2 julio, 1657: «esta es materia llana y practicada en lo pasado, de manera que no necesitava de nueva declaración», indicó el monarca a su lugarteniente.

54. CANET, T.: «Ministros de capa y espada: ¿Integración nobiliaria o manipulación monárquica?», en Andres, F. y Franch, R. (eds.): Cambios y resistencias sociales en la Edad Moderna. Un análisis comparativo entre el centro y la periferia, Madrid, Edit. Sílex, 2014, pp. 303-312. 
de moderación del arbitrio virreinal en esos ejercicios, gracias a la intervención de un cuerpo asesor enriquecido con la presencia de militares que aportarían una visión complementaria a la de los letrados en la determinación de aquel tipo de materias. No podemos dejar de reseñar que en la tipología delictiva objeto de tales medidas de gracia, tenían una significativa presencia los bandos, el bandolerismo y el uso de armas prohibidas. Cuestiones en las que las élites del reino estuvieron ampliamente implicadas. Actuar medidas de gracia para el acompañamiento de la represión judicial de tales ilícitos penales entrañaba un complejo juego de equilibrios para el que se requería un delicado consenso.

Esta misma reflexión resulta extensible al ejercicio de la potestad de gobierno de los virreyes, con la diferencia de que, frente a la graciosa, aquella nunca experimentó las restricciones establecidas sobre esta última. Constatada la profusa utilización de la «económica» por parte de los virreyes que gobernaron el reino en el siglo XVII, la integración de la nobleza local en el proceso de decisión de las medidas a tomar y a quién infligirlas pudo neutralizar, en cierto modo, la unanimidad de las oposiciones suscitadas hasta entonces por su aplicación. La constatación de ese efecto durante el mandato del virrey duque de Montalto permite sustentar esta tesis ${ }^{55}$. Un efecto extendido a otras actuaciones políticas de los virreyes sobre los demás sectores y ámbitos, que abarcarían desde la esfera de la política municipal a la de las familiaturas inquisitoriales. En suma, moderación del arbitrio virreinal y disciplinamiento estamental, destacan como efectos sobresalientes de una medida planteada en el momento de su concesión como gracia del monarca al reino.

La orientación social otorgada al crecimiento de la plantilla del Consejo regnícola sugiere también otra hipótesis interpretativa que deberá, no obstante, ser corroborada con el estudio prosopográfico de los consejeros de capa y espada en la Audiencia valenciana. Los titulares de las citadas plazas parecen adscritos a los sectores medios y bajos de la nobleza valenciana, siguiendo en ello la misma tendencia que manifiestan las adjudicaciones de cargos en las Gobernaciones del reino de Valencia ${ }^{56}$. Si a comienzos del período moderno, los órganos de administración y gobierno se «poblaban» con letrados cuya condición social fue mejorada en función del servicio, la carrera de los militares, en estos niveles medios e inferiores que hemos señalado, parecía encontrar en el ascenso a la Audiencia la culminación más brillante posible de sus cursus honorum. «Hombres medianos» por el punto de partida de sus respectivas raíces sociales, en ambos casos, y servidores públicos en diferentes dimensiones, coincidieron finalmente en el superior órgano de gobierno del reino. ¿Para qué?

Parece fuera de duda el efecto de moderación, complemento y apoyo a la acción de gobierno de los lugartenientes reales. Revisada la nómina de estos a lo largo del

55. Estas conclusiones en CANET, T.: «Ministros de capa y espada...», pp. 306-310.

56. La mejor conocida es sin duda la de Orihuela gracias a las investigaciones de BernABÉ GIL, D. Para el aspecto que ahora interesa, remito a su trabajo: «Nobles valencianos al servicio regio. La provisión del oficio de Portantveus de Governador ultra Sexonam en la Edad Moderna», en Revista de Historia Moderna. Anales de la Universidad de Alicante, n. ${ }^{\circ} 26$ (2008), pp. 13-60. 
XVII, observamos no sólo su crecido número, en relación a la centuria precedente, sino también su adscripción mayoritaria a la alta nobleza ${ }^{57}$. Gran parte de ellos eran personajes completamente ajenos al territorio que administraban en nombre del soberano; pero en los que era necesario delegar las amplísimas funciones propias de la representación regia. Sociológicamente, los cambios en la naturaleza de la Audiencia provocados con las creaciones de 1645 introducían también un cierto equilibrio en el seno de la nobleza al asociar a miembros de sus niveles intermedios a las tareas políticas del más alto nivel dentro del territorio. Una asociación trocada en control y vigilancia, insensible, si se quiere, pero cierta, sobre los mismos lugartenientes reales por parte del Consejo regnícola. Y, en el reverso del efecto, una mayor defensa de lugartenientes reales frente a los embates regnícolas, formulados a través de denuncias de contrafueros, gestionadas -también desde 1645- por la correspondiente Junta ${ }^{58}$ creada en aquella legislatura.

Finalmente, desde el sistema de alianzas y clientelas tejido en el ambiente social y político valenciano, el nuevo entramado del alto tribunal y Consejo del reino constituía, sin duda, una vía para el control de las propias élites locales y, en especial, del belicoso estamento nobiliario. De ahí deriva el componente de manipulación por parte de la propia monarquía que se desprende de la concesión graciosa de 1645. La faceta de culminación de la integración nobiliaria en el servicio regio, que a todas luces encierra la creación de las plazas de capa y espada, no puede ocultar el efecto instrumental de la medida de cara a la propia nobleza local. Los agentes más fieles a la corona dentro de la misma pasarán a convertirse en elementos activos de la política de control y disciplinamiento del colectivo nobiliario, en particular, y estamental en general. Pasarán a colaborar y orientar, en unión de la magistratura - promocionada socialmente por fuerza del servicio- las actuaciones correctivas de los virreyes aplicadas en uso de sus facultades de gracia y gobierno $y$, muy especialmente de la potestad económica. ${ }^{59}$

La aproximación al tema hasta aquí ensayada no cierra, en absoluto, los múltiples interrogantes e hipótesis que la materia sugiere. Esta es todavía una investigación abierta. Además, el presente estudio se ha planteado un recorrido cronológico centrado mayormente en la década posterior a la de creación de las plazas de capa y espada. En ese marco, la riqueza informativa devengada por la meticulosidad del virrey Montalto en el ejercicio de su gobierno ha permitido presentar un rico abanico de problemas, situaciones y soluciones. La ampliación del trabajo en el tiempo permitirá completarlas; pero las referidas constituyen, sin duda, un buen punto de partida con el que enriquecer la historia de la Audiencia real en la Valencia foral moderna.

57. La relación de virreyes de Valencia en el período moderno en Reglá, J., Fuster, J., García Martínez, S., Simó, T., y Climent, J.: Història del Paìs valencià. De les Germanies a la Nova Planta, Barcelona, 1975, pp. 128-130.

58. GUIA, L1.: Cortes del reinado de Felipe IV...,pp. 138-144.

59. Sobre la manipulación y el disciplinamiento nobiliario por esta vía: CANET, T.: «Ministros de capa y espada», pp. 303-312. 